\title{
Anti-inflammatory activity of the basolateral fraction of Caco-2 cells exposed to a rosemary supercritical extract
}

\author{
E.Arranz, J.Mes, H.J.Wichers, L.Jaime, J.A.Mendiola, G.Reglero, S.Santoyo
}

https://doi.org/10.1016/j.jff.2015.01.015

\section{Highlights}

- Uptake of carnosic acid and carnosol from rosemary supercritical extract.

- Basolateral fraction of the extract showed an important anti-inflammatory activity.

- The extract could be used in formulations for prevention of inflammatory diseases.

\section{Abstract}

The anti-inflammatory activity of the basolateral fraction of Caco-2 cells exposed to a rosemary supercritical extract was examined. Uptake of rosemary extract fractions was tested on Caco-2 cell monolayers (2-12 h incubation times) and the quantification of carnosic acid and carnosol was performed by UPLC-MS/MS.

15 Human macrophages were treated with the basolateral fractions and secretion of TNF- $\alpha$, IL-1 $\beta$, IL-6 and IL10 was measured by ELISA. The fractions obtained after 8 and $12 \mathrm{~h}$ in absorption experiments caused a significant reduction in excretion of the pro-inflammatory cytokines. This reduction in cytokine secretion levels corresponded to the amounts of carnosic acid and carnosol in the basolateral fractions. Thus, the basolateral fraction of a rosemary supercritical extract showed an important anti-inflammatory activity, providing the basis for increasing the use of supercritical rosemary extracts for the prevention of inflammatory diseases.

\section{Keywords}

Rosemary

Bioavailable fraction

Anti-inflammatory activity

Supercritical extraction 


\section{Introduction}

30 The inflammatory process is a coordinate non-specific response of the immune system induced by a variety of external (microbial) factors or by endogenous products resulting from e.g. cell lysis. Early stages of the counteracting response include the activation of macrophages that secrete signaling molecules, cytokines, as TNF- $\alpha$, IL-1 $\beta$ or IL-6 with pro-inflammatory activity or IL-10 with anti-inflammatory effect (Barton, 2008; Zhang, 2008). The main function of inflammation is to resolve an infection or repair the damage and restore homeostasis. However, if the regulation of the response fails and develops into a chronic response, the risk of diseases increases such as e.g. atherosclerosis, diabetes, cancer, rheumatoid arthritis or Alzheimer (Akiyama et al., 2000; Medzhitov, 2008; Nathan, 2002). Nowadays anti-inflammatory drugs are on the market that, however, usually exhibit undesirable co-morbidity (Waldner \& Neurath, 2009). Food-contained components with anti-inflammatory properties may be attractive in developing nutritional products that can be used in controlling undesirable inflammatory conditions. Consequently, there is an interest for the incorporation of ingredients with beneficial health properties in the food industry that contributes to the treatment or prevention of chronic inflammatory diseases (Sergent, Piront, Meurice, Toussaint, \& Schneider, 2010; Zorrilla et al., 2014).

Rosmarinus officinalis L. (rosemary) extracts have been extensively studied since they have been reported to possess antioxidant, antimicrobial, antitumor and anti-inflammatory activities (Ben Jemia et al., 2013; del Pilar Sánchez-Camargo et al., 2014; Dilas et al., 2012; Santoyo et al., 2005; Viuda-Martos, Ruiz-Navajas, Fernandez-Lopez, \& Perez-Alvarez, 2008; Yu et al., 2013). These activities have frequently been attributed to the presence of carnosic acid and carnosol, major phenolic diterpenoid components of rosemary leaves (Rau et al., 2006). Kuo et al. (2011) demonstrated that the inhibitory effects of carnosic acid on LPS-induced 50 NO and TNF- $\alpha$ production are related to the suppression of iNOS and COX-2 expression, resulting from inhibition of NF- $\kappa$ B signaling. Carnosol decreases LPS-induced iNOS mRNA and down-regulates the inhibitor NF- $\kappa$ B kinase activity in the mouse macrophage RAW 264.7 cell line (Lo, Liang, Lin-Shiau, Ho, \& Lin, 2002). Besides, several authors have reported that rosemary extracts or fractions show a similar or superior anti-inflammatory activity than do carnosic acid or carnosol alone (Yu et al., 2013). To be able to extrapolate results found in vitro to in vivo situation it is important to know in vivo stability, metabolization and bioavailability of rosemary compounds. Doolaege, Raes, De Vos, Verhe, and De Smet (2011) identified carnosic acid in the blood of rats after oral administration. Soler-Rivas et al. (2010), using an in vitro digestion/Caco-2 cell culture model, found no transport across these intestinal cell layer of carnosic acid but only of methyl carnosate. This warrants further research directed to bioavailability of these compounds.

60 The extraction of rosemary leaves using supercritical CO2 has been intensively investigated in order to obtain a high percentage of phenolic diterpenes, mainly carnosic acid and carnosol (Carvalho, Moura, Moura, Rosa, \& Meireles, 2005; Chang et al., 2008). Several authors have compared supercritical rosemary extracts with the extracts obtained using liquid solvents (ethanol, acetone and hexane) and hydrodistillation. Supercritical extracts presented the highest recovery of carnosic acid compared with the conventional solvent methods (Carvalho et al., 2005). Despite these data, only a few studies have evaluated the antiinflammatory activity of supercritical rosemary extracts (Kuo et al., 2011; Peng et al., 2007).

The aim of this work was to study the anti-inflammatory activity of the basolateral fraction of Caco-2 cells exposed to a supercritical rosemary extract. In order to simulate the in vivo situation we incorporated the extract to polarized Caco-2 cells grown in a Transwell ${ }^{\circledR}$ plate and subsequently the transported basolateral 70 fraction was exposed to LPS-activated human macrophages (THP-1). Besides, the fate of carnosic acid and carnosol was analyzed. Moreover, in this paper we also studied the anti-inflammatory activity of the 
basolateral fraction of a mixture of carnosic acid and carnosol in an attempt to establish a relationship between the anti-inflammatory activity of the extract and these compounds.

\section{Materials and methods}

\subsection{Chemicals}

Carnosol (>95\%) was purchased from Sigma-Aldrich (Madrid, Spain) while carnosic acid ( $\geq 97 \%)$ was supplied from Fluka (Madrid, Spain). Ethanol and phosphoric acid (85\%) in HPLC grade were purchased from Panreac (Barcelona, Spain) and acetonitrile was obtained from Lab Scan (Dublin, Ireland). $\mathrm{CO}_{2}(\mathrm{~N} 38)$ was supplied from Carburos Metálicos (Madrid, Spain). Purified water was obtained from a Milli-Q purification system (Millipore, Madrid, Spain).

\subsection{Rosemary samples and extraction}

Rosemary ( $R$. officinalis L.) samples consisted in dried leaves were obtained from an herbalist's shop (Murcia, Spain). Cryogenic grinding of the samples was performed under liquid nitrogen and the ground material was sieved to the appropriate size (between 200 and $600 \mu \mathrm{m}$ ).

85 Supercritical rosemary extract was obtained using a pilot-plant supercritical fluid extractor (Thar Technology, Pittsburgh, PA, USA, model SF2000), comprising a 2 L cylinder extraction cell and two different separators ( $\mathrm{S} 1$ and $\mathrm{S} 2$ ), each of $0.5 \mathrm{~L}$ capacity, with independent control of temperature and pressure. The extraction vessel was packed with $0.5 \mathrm{~kg}$ of the cryogenically milled and sieved plant particles. The extraction was performed at $15 \mathrm{MPa}$ and $313 \mathrm{~K}$ using $60 \mathrm{~g} / \mathrm{min} \mathrm{CO}_{2}$ flow rate and $5 \% \mathrm{w} / \mathrm{w}$ ethanol was employed as cosolvent during $180 \mathrm{~min}$ of extraction to obtain one sample from $\mathrm{S} 1$ without fractionation.

\subsection{Chemical characterization of supercritical rosemary extract}

HPLC analysis was carried out to determine carnosic acid and carnosol content in the rosemary extract, using a Varian Pro-star equipped with a Microsorb-100 C18 column (Varian, Madrid, Spain). Mobile phase consisted of acetonitrile (solvent A) and $0.1 \%$ of phosphoric acid in water (solvent B) applying the following gradient: from $0 \mathrm{~min}$ to $8 \mathrm{~min}, 23 \% \mathrm{~A}$; increasing from $8 \mathrm{~min}$ to $25 \mathrm{~min}$ up to $75 \% \mathrm{~A}$; kept constant during $15 \mathrm{~min}$, and from $40 \mathrm{~min}$ to $45 \mathrm{~min}$, initial conditions were gained (23\% A). The detection was accomplished by using a diode array detection system (Varian, Madrid, Spain) storing the signal at a wavelength of 230, 280 and $350 \mathrm{~nm}$. Samples were analyzed in duplicate and the obtained average standard deviation was $\pm 0.13 \%$.

\subsection{Caco-2 experiments}

Caco-2 cells (American Type Culture Collection, ATCC, Barcelona, Spain) were maintained in Dulbecco's Modified Eagle's Medium (DMEM) supplemented with 10\% FBS, $100 \mathrm{U} / \mathrm{mL}$ penicillin, $100 \mathrm{mg} / \mathrm{mL}$ streptomycin, 1\% nonessential amino acids and $2 \mathrm{mM}$ L-glutamine (Invitrogen, Madrid, Spain) at $37^{\circ} \mathrm{C}$ in a humidified atmosphere containing $5 \% \mathrm{CO}_{2}$.

The cytotoxic effect of the supercritical rosemary extract and the mixture of carnosic acid and carnosol on Caco-2 cells was tested using 3-(4,5-dimethylthiazol-2-yl)-2,5-diphenyl tetrazolium bromide (MTT) assay (Sigma), following Mosmann's (1983) method. 
For transport experiments, Caco- 2 cells were seeded onto twelve-well Transwell ${ }^{\circledR}$ plates $(0.4 \mu \mathrm{m}$ pore size, inserts of $12 \mathrm{~mm}$ diameter, Costar, Corning, Madrid, Spain) at a density of $2 \times 10^{4}$ cells per insert. The cells were maintained along 21 days, once the monolayer was formed. The integrity of the monolayer was checked by measuring the transepithelial electrical resistance (TEER) (Evon World Precision Instruments, Sarasota, FL, USA). Supercritical rosemary extract or the standards mixture were incorporated in the apical compartment of the Transwell ${ }^{\circledR}$ plate at a concentration of $20 \mu \mathrm{g} / \mathrm{mL}(10 \mu \mathrm{g}$ per well) and incubated for 2,4 , 8 and $12 \mathrm{~h}$ at $37^{\circ} \mathrm{C}$. Then, the apical and basolateral samples were collected and stored at $-20^{\circ} \mathrm{C}$ prior analysis. Cell monolayer was also recovered after the experiments and stored at $-20^{\circ} \mathrm{C}$.

\subsection{Quantification of carnosic acid and carnosol in fractions after absorption experiments}

The apical and basolateral samples from Transwell ${ }^{\circledR}$ compartments, after the different incubation times, were freeze dried. The powder obtained was re-suspended in ethanol and centrifuged. Caco- 2 cell monolayer samples were centrifuged and the pellet was re-suspended in acetone and sonicated to facilitate disruption of the cells. Finally samples were dried under nitrogen and dissolved in ethanol.

UPLC-MS/MS was employed to detect carnosic acid and carnosol in the apical, basolateral and cell lysates samples, specifically an Accela (Thermo Scientific, San Jose, CA, USA) liquid chromatograph equipped with a DAD and an autosampler. The chromatograph was coupled to a TSQ Quantum (Thermo Scientific) triple quadrupole analyzer via an electrospray interface. The analytical conditions employed consisted of the use of a Hypersil Gold column $(50 \mathrm{~mm} \times 2.1 \mathrm{~mm}$, d.p. $1.9 \mathrm{~m})$ (Thermo Scientific) using as mobile phases acetonitrile ( $0.1 \%$ formic acid, $\mathrm{A})$ and water $(0.1 \%$ formic acid, $\mathrm{B})$ eluted according to the following gradient: $0 \mathrm{~min}, 95 \% \mathrm{~B}$; $0.35 \mathrm{~min}, 95 \% \mathrm{~B} ; 3.5 \mathrm{~min}, 40 \% \mathrm{~B} ; 6.2 \mathrm{~min}, 5 \% \mathrm{~B} ; 6.5 \mathrm{~min} ; 5 \% \mathrm{~B} ; 7 \mathrm{~min}, 95 \% \mathrm{~B}$; $9 \mathrm{~min}, 95 \%$ B (Herrero, Plaza, Cifuentes, \& Ibáñez, 2010). The flow rate was $0.4 \mathrm{~mL} / \mathrm{min}$ while the injection volume was $10 \mu \mathrm{L}$. The diode array detector recorded the spectra from 200 to $450 \mathrm{~nm}$. In order to quantify carnosic acid and carnosol, the mass spectrometer was operated in the negative ESI multiple reaction monitoring (MRM) with a Q1 and Q3 resolution of 0.7 Da FWHM using scan width 0.010 Da and scan time of $0.040 \mathrm{~s}$. Carnosic acid and carnosol transitions were optimized by direct infusion of pure standards. Parent mass of carnosic acid was 331.049 with an ion product mass of 287.175, using a collision energy of 21 and tube lens of 59, while carnosol parent mass was 329.198 with an ion product mass of 285.199, using a collision energy of 17 and tube lens of 51. Carnosic acid and carnosol concentrations in the samples were performed from calibration curves determined by linear regression.

\subsection{Anti-inflammatory activity of basolateral samples from Caco-2 experiments}

Human THP-1 monocytes (American Type Culture Collection, ATCC) were cultured in RPMI 1640 culture medium supplemented with $10 \% \mathrm{FBS}, 100 \mathrm{U} / \mathrm{mL}$ penicillin, $100 \mathrm{mg} / \mathrm{mL}$ streptomycin, $2 \mathrm{mM}$ L-glutamine (Invitrogen) and $0.05 \mathrm{mM} \beta$-mercaptoethanol (Sigma-Aldrich) at $37{ }^{\circ} \mathrm{C}$ in $95 \%$ humidified air containing $5 \%$ $\mathrm{CO}_{2}$. Cells were plated at a density of $5 \times 10^{5}$ cells $/ \mathrm{mL}$ in 24 well plates. Differentiation to macrophages (THP-1/M cells) was induced by maintaining the cells in the presence of $100 \mathrm{ng} / \mathrm{mL}$ phorbol 12 -myristate 13-acetate (PMA) (Sigma-Aldrich) for $48 \mathrm{~h}$. After differentiation, cells were washed with PBS and incubated with $0.05 \mu \mathrm{g} / \mathrm{mL}$ LPS (Sigma-Aldrich) in presence of the basolateral medium from Caco-2 cells experiments for $24 \mathrm{~h}$. Then, the supernatant was frozen at $-80^{\circ} \mathrm{C}$.

The release of IL-1 $\beta$, IL-10, IL-6 and TNF- $\alpha$ was measured in the supernatants of THP-1/M cells using ELISA kits (BD Biosciences, Madrid, Spain), according to manufacturer's instructions. The color generated was determined by measuring the OD at $450 \mathrm{~nm}$ using a multiscanner autoreader (Sunrise Tecan, Barcelona, Spain).

\subsection{Statistical analysis}


All data were expressed as the mean of three determinations \pm SD. Data were analyzed by one-way analysis of variance (ANOVA) followed by Dunnett's and Bonferroni tests, using Prism program for Windows (Version 5; GraphPad Software, San Diego, CA, USA). P values lower than 0.05 were considered significant.

\section{Results and discussion}

\subsection{Analysis of supercritical rosemary extract}

A supercritical rosemary extract was obtained from a pilot scale plant using $5 \%$ of ethanol as a cosolvent, a pressure of $15 \mathrm{MPa}$ and $313 \mathrm{~K}$. These conditions were identical to conditions used in earlier studies by our research group, in order to obtain extracts with a high quantity of carnosic acid and carnosol (Vicente, Martín, García-Risco, Fornari, \& Reglero, 2012). The HPLC analysis of the extract showed that the carnosic acid-content of the extract was $256 \mathrm{mg} / \mathrm{g}$, while for carnosol this was $38 \mathrm{mg} / \mathrm{g}$. These results indicated that the extract used in this work contained a higher quantity of carnosic acid than present in supercritical extracts that were used to carry out previous anti-inflammatory studies. Meanwhile carnosol content was similar or slightly higher than that previously reported (Kuo et al., 2011; Peng et al., 2007).

\subsection{Determination of carnosic acid and carnosol in apical, basolateral and cellular fractions}

A supercritical rosemary extract was obtained from a pilot scale plant using $5 \%$ of ethanol as a cosolvent, a pressure of $15 \mathrm{MPa}$ and $313 \mathrm{~K}$. These conditions were identical to conditions used in earlier studies by our research group, in order to obtain extracts with a high quantity of carnosic acid and carnosol (Vicente, Martín, García-Risco, Fornari, \& Reglero, 2012). The HPLC analysis of the extract showed that the carnosic acid-content of the extract was $256 \mathrm{mg} / \mathrm{g}$, while for carnosol this was $38 \mathrm{mg} / \mathrm{g}$. These results indicated that the extract used in this work contained a higher quantity of carnosic acid than present in supercritical extracts that were used to carry out previous anti-inflammatory studies. Meanwhile carnosol content was similar or slightly higher than that previously reported (Kuo et al., 2011; Peng et al., 2007).

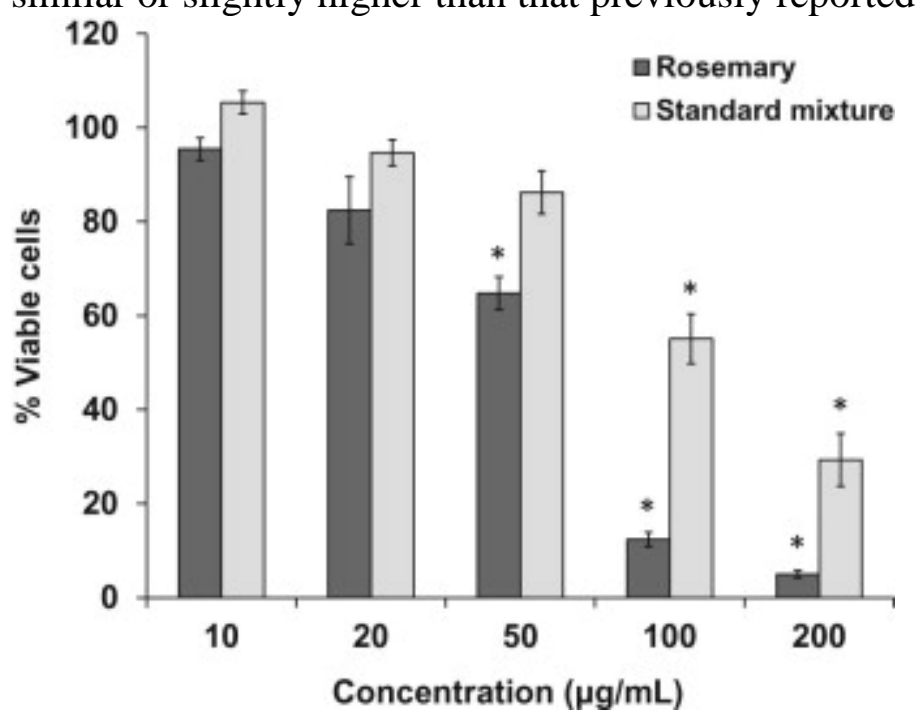

Fig. 1. Viability (\%) of Caco-2 cells after $12 \mathrm{~h}$ of incubation with rosemary extract or standard mixture of carnosic acid and carnosol. Control cells were grown in media with no treatment. *Denotes statistical differences between control cells and the other samples at $p<0.05$.

The percentage of carnosic acid and carnosol detected in the exposure experiments is shown in Fig. 2. When rosemary supercritical extract was added to Caco- 2 cells, after $2 \mathrm{~h}$ the percentage of carnosic acid that was unabsorbed was approximately $75 \%$ of the initial amount. The amount detected in the cellular fraction 
represented approx. $20 \%$ of carnosic acid that was added. An increase in the incubation time (4h) caused a small reduction in the percentage of carnosic acid that was detectable in the apical compartment until $70 \%$, while in the cellular samples the detectable amount increased to $30 \%$. After $8 \mathrm{~h}$ of incubation, carnosic acid was detected also in the basolateral compartment (12\% of the added amount), which increased to $25 \%$ after $12 \mathrm{~h}$. The increase in the transport of carnosic acid across the Caco- 2 cells barrier between 8 and $12 \mathrm{~h}$, seems to be released from the cellular content, as no further decrease was found in the apical concentration.

Carnosol was detected inside the cells only after $4 \mathrm{~h}$. After longer incubation $(8 \mathrm{~h})$, the carnosol content inside the enterocytes was increased to $8 \%$, and after $12 \mathrm{~h}$ up to $20 \%$. Uptake carnosol $(3 \%$ of the initial concentration added) was only found after $12 \mathrm{~h}$.

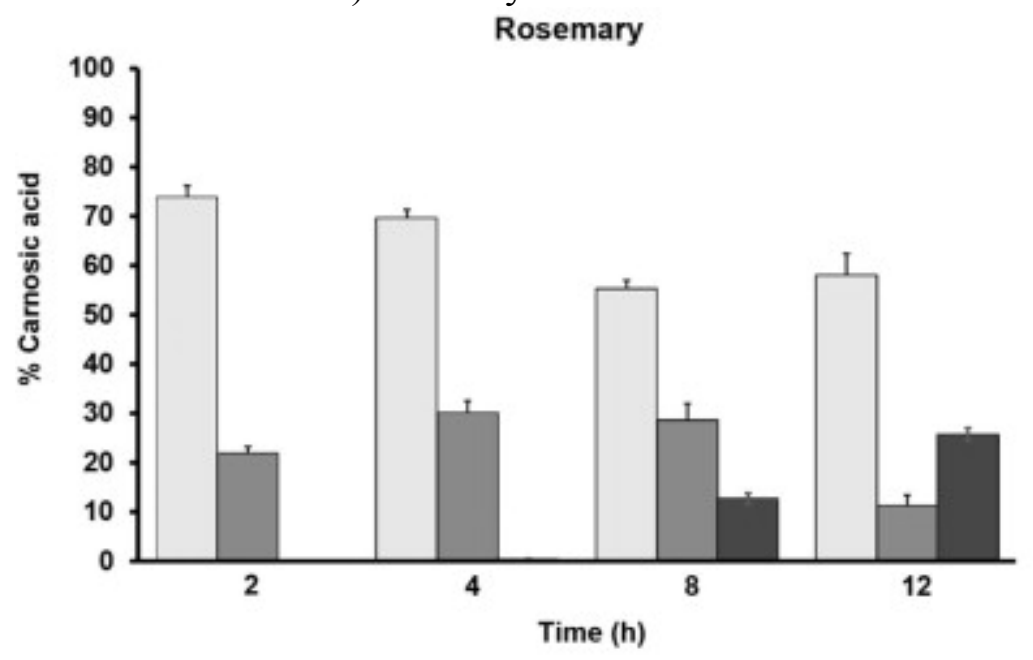

(A)

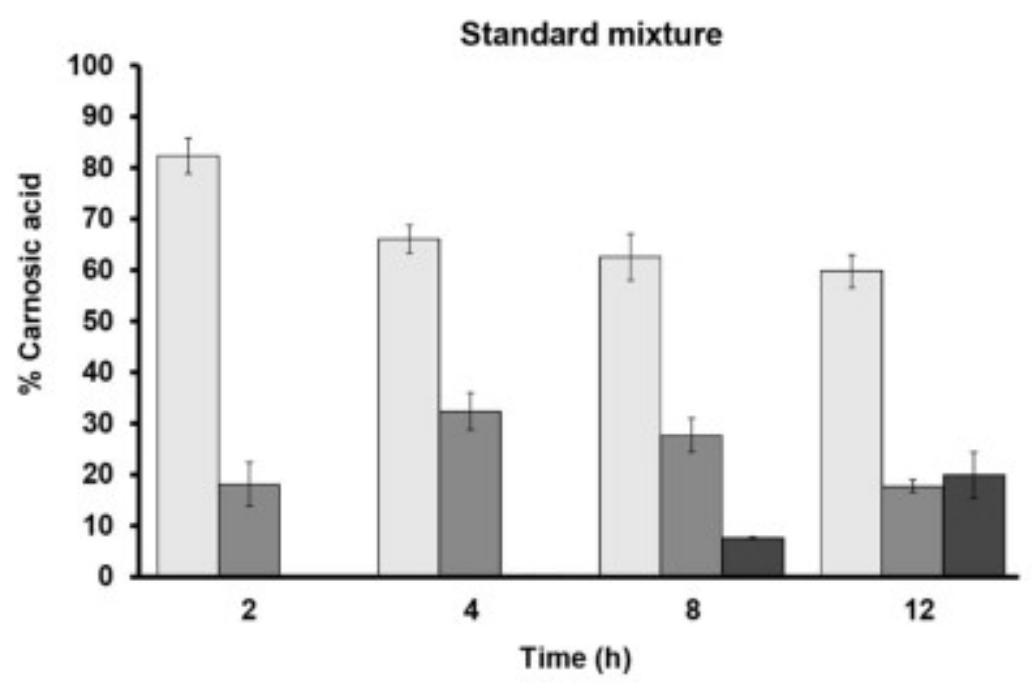

(C)

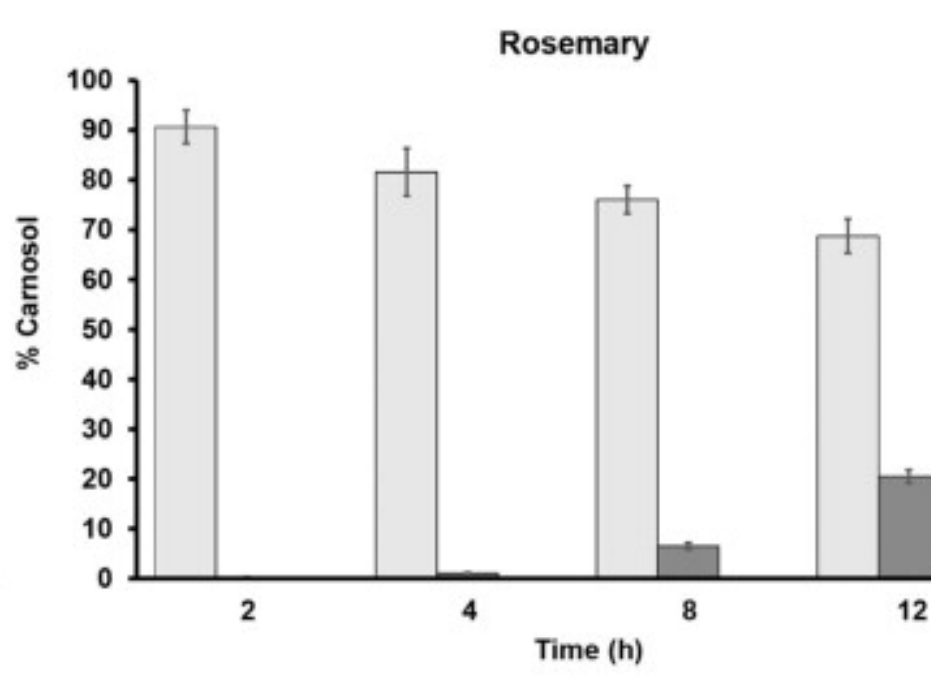

(B)

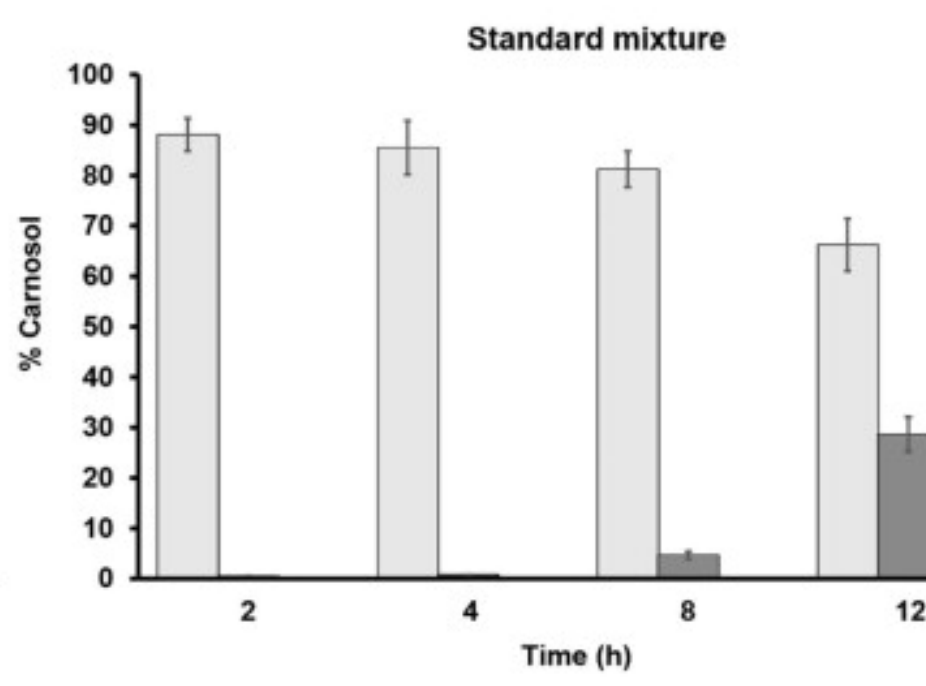

(D)

$\square$ Apical $\square$ Cells $\square$ Basolateral

Fig. 2. Carnosic acid (A and C) and carnosol (B and D) percentage recovered from the apical compartment, cells cytoplasm and basolateral compartment from the Transwell ${ }^{\circledR}$ plate after supercritical rosemary extract or standard mixture application at different incubation times.

Fig. 2 also showed the results obtained in the exposure experiments using a mixture of carnosic acid and carnosol at the same concentration in which these compounds were presented in the rosemary extract. The results obtained with this mixture were similar to those obtained from rosemary extract. After $2 \mathrm{~h}$, almost 
$20 \%$ of the initial concentration of carnosic acid could be found in the cytoplasm of the cells. After longer incubation times, the carnosic acid in the cellular fraction was increased (30\% after $4 \mathrm{~h}, 20 \%$ after 8 and $12 \mathrm{~h}$ ). Carnosic acid was detected in the basolateral fraction to a maximum of $20 \%$ of the added amount. Finally, carnosol was transported in a low proportion and after $12 \mathrm{~h}$ it was found in a low percentage in the basolateral compartment of the Transwell ${ }^{\circledR}$ plates.

These results indicated that carnosic acid and carnosol presented in the rosemary extract showed the same pattern of transport to the mixture of the pure compounds. Furthermore, there was an uptake of carnosic acid to a relevant percentage (20-25\%). The bioavailability of this compound has been also reported by Doolaege et al. (2011). These authors indicated that the gastrointestinal absorption of carnosic acid was slow, with a maximum after more than 125 min of treatment and $40 \%$ of bioavailability. Similar results were obtained by Yan et al. (2009) after intra-gastric administration of $90 \mathrm{mg} / \mathrm{kg}$ of carnosic acid in rats. These authors also reported a slow gastrointestinal absorption and claimed a bioavailability of $65 \%$ for carnosic acid in plasma samples. Furthermore, Krause and Ternes (2000) evaluated the carnosic acid content in egg yolk after the supplementation of hen diet with a rosemary extract. However, previous studies in our research group (Soler-Rivas et al., 2010), could not detect carnosic acid and carnosol in the transwell plates basolateral compartment, probably due to the lower sensibility of the analytic method, HPLC-DAD versus UPLCMS/MS.

\subsection{Anti-inflammatory activity of the bioavailable fractions}

The anti-inflammatory activity of the bioavailable fractions was determined by exposing the basolateral media to THP-1 macrophages. In the present work, this system was used instead of a direct co-culturing Caco-2 and THP-1 since Watanabe, Satsu, Mochizuki, Nakano, and Shimizu (2004) reported that TNF- $\alpha$ produced by macrophages could disrupt the epithelial barrier in a co-culture in transwells of Caco-2 cells and THP-1/M.

During the transport experiments at 2 to $12 \mathrm{~h}$, basolateral compartment of the transwell plates was collected, incubated with LPS-activated macrophages during $24 \mathrm{~h}$ and cytokines secretion was measured by ELISA. The results for TNF- $\alpha$, IL-1 $\beta$, IL-6 and IL-10 secretion are presented in Fig. 3 . The addition of the basolateral fraction from rosemary extract obtained after 2 and $4 \mathrm{~h}$ of Caco-2 uptake experiments, did not induce changes in the cytokine secretion, compared with levels obtained for positive control (macrophages activated with LPS). These results are in agreement with carnosic acid and carnosol being not detectable in the basolateral medium after 2 and $4 \mathrm{~h}$. However, when the basolateral fraction, collected after $8 \mathrm{~h}$ was added to the activated macrophages, a significant reduction in all measured cytokines was found, and even more strongly for IL-6. Furthermore, the incubation of activated macrophages with the absorbed fraction of rosemary extract after $12 \mathrm{~h}$, reduced the secretion of TNF- $\alpha$, IL-1 $\beta$, IL-6 and IL-10 very considerably, 50\% or more. The results indicated that inhibition of the secretion of measured cytokines by 8 and $12 \mathrm{~h}$ basolateral fractions of rosemary extract, correlated to an increase in carnosic acid in the fractions. Also, to a lesser extent, it correlated to the small amount of carnosol detected after $12 \mathrm{~h}$ in the basolateral samples. 
TNF-a

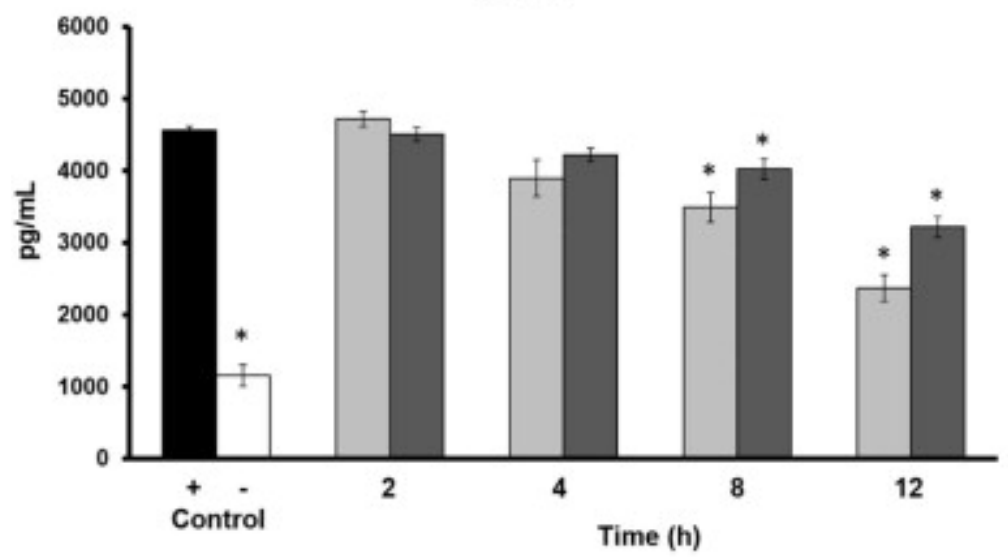

(A)

IL-6

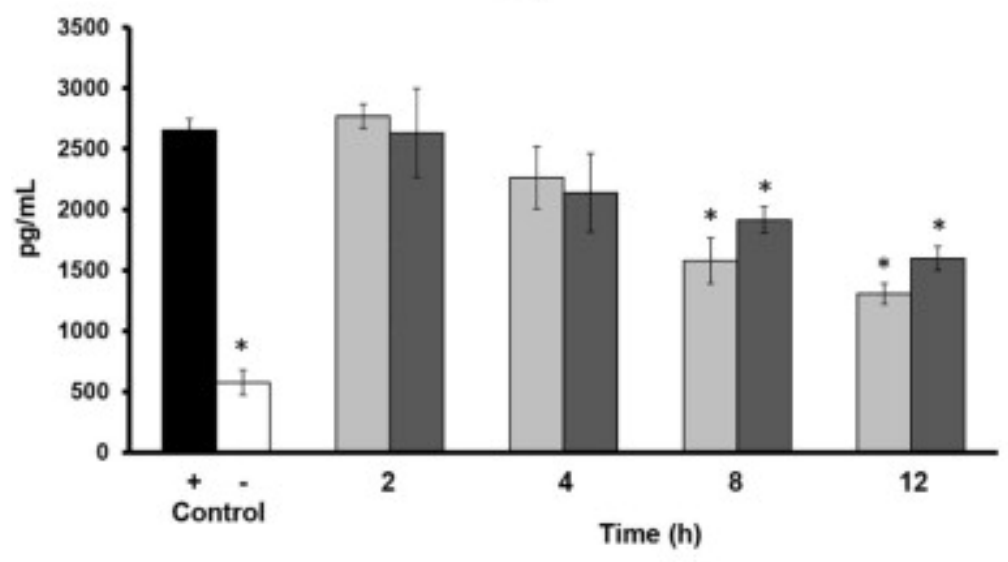

(C)

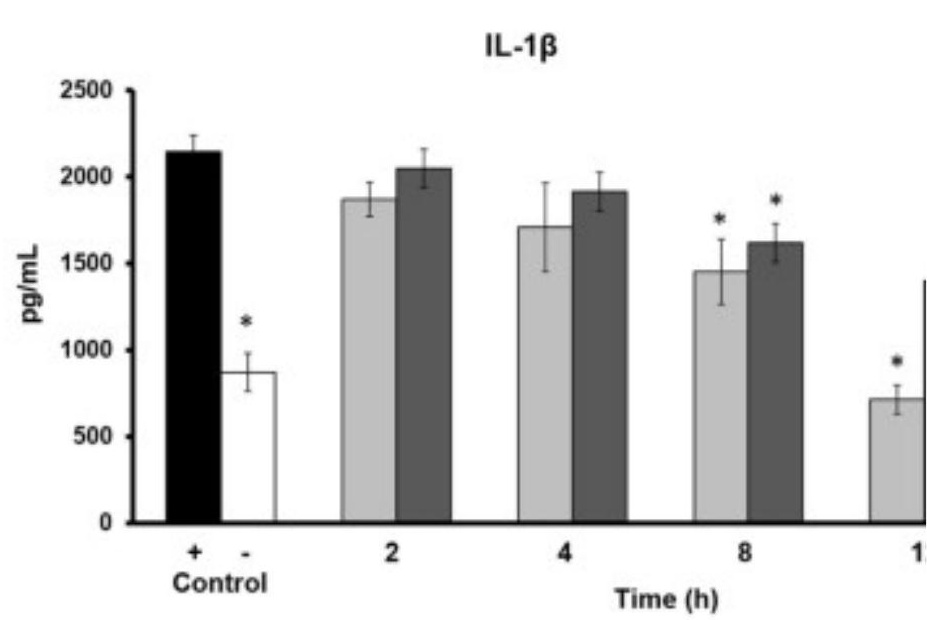

(B)

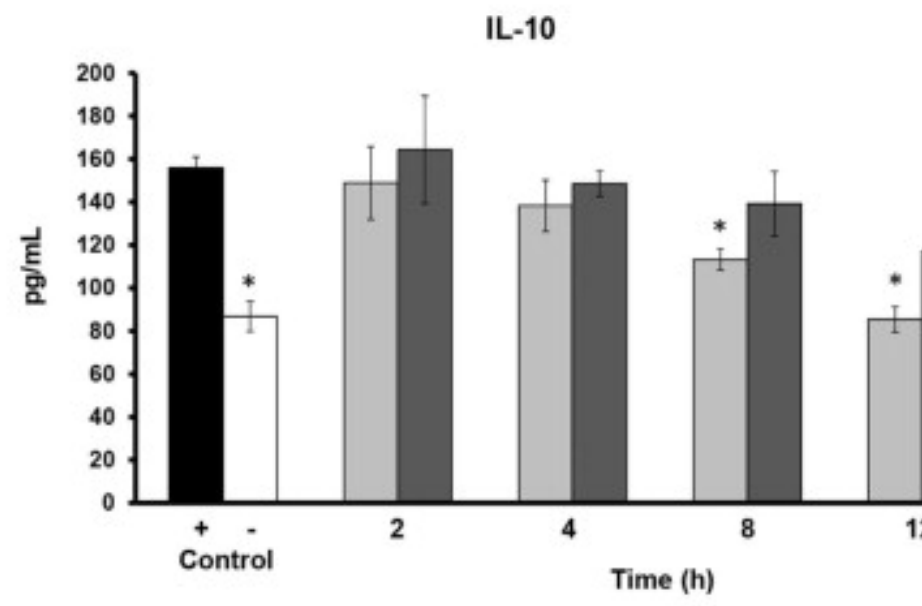

(D)

-Control $+\square$ Control - $\square$ Rosemary $\square$ Standard mixture

Fig. 3. Concentration of TNF- $\alpha$ (A), IL-1 $\beta$ (B), IL-6 (C) and IL-10 (D) secreted by THP-1/M activated with LPS in presence of the bioavailable fractions of supercritical rosemary extract or standard mixture. Each bar is the mean of three determinations \pm standard deviation. *Denotes statistical differences between Control+LPS and the other samples at $p<0.05$.

In order to determine if the inhibition in the secretion of measured cytokines was only related to the presence of carnosic acid and carnosol in the basolateral fractions, the anti-inflammatory activity of the basolateral fraction of the mixture of carnosic acid and carnosol was also determined under the same conditions. The data also showed that only fractions obtained after 8 and $12 \mathrm{~h}$ decreased the secretion levels of all the cytokines tested, although in a lesser extent than when rosemary extract was employed.

These results demonstrated that the basolateral fraction from rosemary supercritical extract and the mixture of carnosic acid and carnosol presented an important anti-inflammatory activity, since both reduced the secretion of the pro-inflammatory cytokines TNF- $\alpha$, IL-1 $\beta$ and IL-6. However, the anti-inflammatory activity of the basolateral fraction of rosemary extract was higher than the fraction from the mixture of carnosic acid and carnosol, indicating that in the rosemary extract other compounds with anti-inflammatory activity were presented either derived from the exposed sample or due to compounds secreted by Caco- 2 as a response to the challenge. Earlier work developed from our research group described the presence of compounds as 1,8-cineole or camphor in the supercritical rosemary extract (Fornari, Vicente, Vázquez, 
García-Risco, \& Reglero, 2012), for which anti-inflammatory activity has been reported previously (Ehrnhöfer-Ressler et al., 2013; Santos \& Rao, 2000). Moreover, Atul Bhattaram, Graefe, Kohlert, Veit, and Derendorf (2002) and Boyle, McLean, Brandon, and Wiggins (2005) reported the bioavailability of 1,8cineole.

In conclusion, the results demonstrated that carnosic acid and carnosol included in a supercritical rosemary extract showed the same behavior as a mixture of these compounds. Furthermore, the basolateral fraction of this supercritical extract showed a significant anti-inflammatory activity. These results suggest a possible application of supercritical rosemary extracts, besides flavorants, in formulations for the prevention of inflammatory diseases.

\section{Acknowledgments}

Financial support from Spanish Ministry of Science and Innovation (CICYT) (Project: IPT-300000-2010034), Ingredientes Saludables Mediterráneos Innovadores (INNSAMED) and Comunidad Autónoma de Madrid (ALIBIRD, project S-505/AGR-0153). The authors declare no conflict of interest.

\section{References}

Akiyama H., Barger S., Barnum S., Bradt B., Bauer J., Cole G., Cooper N., Eikelenboom P., Emmerling M., Fiebich B., Finch C., Frautschy S., Griffin W., Hampel H., Hull H., Landreth G., Lue L., Mrak R., Mackenzie I., McGeer P., O'Banion M., Pachter J., Pasinetti G., Plata-Salaman C., Rogers J., Rydel R., Shen Y., Streit W., Strohmeyer R., Tooyoma I., Van Muiswinkel F., Veerhuis R., Walker D., Webster S., Wegrzyniak B., Wenk G., Wyss-Coray T.Inflammation and Alzheimer's disease Neurobiological Aging, 21 (2000), pp. 383-421

Atul Bhattaram V., Graefe U., Kohlert C., Veit M., Derendorf H.Pharmacokinetics and bioavailability of herbal medicinal products

Phytomedicine: International Journal of Phytotherapy and Phytopharmacology, 9 (2002), pp. 1-33

Barton G.M.A calculated response: Control of inflammation by the innate immune system The Journal of Clinical Investigation, 118 (2008), pp. 413-420

Ben Jemia M., Tundis R., Maggio A., Rosselli S., Senatore F., Menichini F., Bruno M., Kchouk M.E., Loizzo M.R.NMR-based quantification of rosmarinic and carnosic acids, GC-MS profile and bioactivity relevant to neurodegenerative disorders of Rosmarinus officinalis L. extracts Journal of Functional Foods, 5 (2013), pp. 1873-1882

Boyle R., McLean S., Brandon S., Wiggins N.Rapid absorption of dietary 1,8-cineole results in critical blood concentration of cineole and immediate cessation of eating in the common brushtail possum (Trichosurus vulpecula)

Journal of Chemical Ecology, 31 (2005), pp. 2775-2790

Carvalho R.N. Jr., Moura L.S., Moura L.S., Rosa P.T.V., Meireles M.A.A.Supercritical fluid extraction from rosemary (Rosmarinus officinalis): Kinetic data, extract's global yield, composition, and antioxidant activity

The Journal of Supercritical Fluids, 35 (2005), pp. 197-204 
Chang C.H., Chyau C.C., Hsieh C.L., Wu Y.Y., Ker Y.B., Tsen H.Y., Peng R.Y.Relevance of phenolic diterneme constituents to antioxidant activity of supercritical $\mathrm{CO}_{2}$ extract from the leaves of rosemary

Natural Products Research, 22 (2008), pp. 76-90

del Pilar Sánchez-Camargo A., Valdés A., Sullini G., García-Cañas V., Cifuentes A., Ibáñez E., Herrero M.Two-step sequential supercritical fluid extracts from rosemary with enhanced antiproliferative activity

Journal of Functional Foods, 11 (2014), pp. 293-303

Dilas S., Knez Z., Cetojevic-Simin D., Tumbas V., Skerget M., Canadanovic-Brunet J., Cetkovic G.In vitro antioxidant and antiproliferative activity of three rosemary (Rosmarinus officinalis L.) extract formulations

International Journal of Food Science and Technology, 47 (2012), pp. 2052-2062

Doolaege E.H., Raes K., De Vos F., Verhe R., De Smet S.Absorption, distribution and elimination of carnosic acid, a natural antioxidant from Rosmarinus officinalis, in rats Plant Foods and Human Nutrition, 66 (2011), pp. 196-202

Ehrnhöfer-Ressler M.M., Fricke K., Pignitter M., Walker J.M., Walker J., Rychlik M., Somoza V.Identification of 1,8-cineole, borneol, camphor, and thujone as anti-inflammatory compounds in a Salvia officinalis $\mathbf{L}$. infusion using human gingival fibroblasts Journal of Agricultural and Food Chemistry, 61 (2013), pp. 3451-3459

Fornari T., Vicente G., Vázquez E., García-Risco M.R., Reglero G.Isolation of essential oil from different plants and herbs by supercritical fluid extraction Journal of Chromatography. A, 1250 (2012), pp. 34-48

Herrero M., Plaza M., Cifuentes A., Ibáñez E.Green processes for the extraction of bioactives from Rosemary: Chemical and functional characterization via ultra-performance liquid chromatography-tandem mass spectrometry and in-vitro assays Journal of Chromatography. A, 1217 (2010), pp. 2512-2520

Krause E.L., Ternes W.Bioavailability of the antioxidative Rosmarinus officinalis compound carnosic acid in eggs

European Food Research and Technology, 210 (2000), pp. 161-164

Kuo C.F., Su J.D., Chiu C.H., Peng C.C., Chang C.H., Sung T.Y., Huang S.H., Lee W.C., Chyau C.C.Anti-inflammatory effects of supercritical carbon dioxide extract and its isolated carnosic acid from Rosmarinus officinalis leaves

Journal of Agricultural and Food Chemistry, 59 (2011), pp. 3674-3685

Lo A.H., Liang Y.C., Lin-Shiau S.Y., Ho C.T., Lin J.K.Carnosol, an antioxidant in rosemary, suppresses inducible nitric oxide synthase through down-regulating nuclear factor- $\kappa B$ in mouse macrophages

Carcinogenesis, 23 (2002), pp. 983-991

Medzhitov R.Origin and physiological roles of inflammation

Nature, 454 (2008), pp. 428-435 
Mosmann T.Rapid colorimetric assay for cellular growth and survival: Application to proliferation and cytotoxicity assays Journal of Immunological Methods, 65 (1983), pp. 55-63

Nathan C.Points of control in inflammation

Nature, 420 (2002), pp. 846-852

Peng C.H., Su J.D., Chyau C.C., Sung T.Y., Ho S.S., Peng C.C., Peng R.Y.Supercritical fluid extracts of rosemary leaves exhibits potent anti-inflammation and anti-tumor effects Bioscience, Biotechnology, and Biochemistry, 71 (2007), pp. 2223-2232

Rau O., Wurglics M., Paulke A., Zitzkowski J., Meindl N., Bock A.Carnosic acid and carnosol, phenolic diterpene compounds of the labiate herbs rosemary and sage, are activators of the human peroxisome proliferator-activated receptor gamma Planta Medica, 72 (2006), pp. 881-887

Santos F.A., Rao V.S.N.Anti-inflammatory and antinociceptive effects of 1,8 cineole a terpenoid oxide present in many plant essential oils

Phytotherapy Research, 14 (2000), pp. 240-244

Santoyo S., Cavero S., Jaime L., Ibañez E., Señorans F.J., Reglero G.Chemical composition and antimicrobial activity of Rosmarinus officinalis L. essential oil obtained via supercritical fluid extraction

Journal of Food Protection, 68 (2005), pp. 790-795

Sergent T., Piront N., Meurice J., Toussaint O., Schneider Y.Anti-inflammatory effects of dietary phenolic compounds in an in vitro model of inflamed human intestinal epithelium Chemico-Biological Interactions, 188 (2010), pp. 659-667

Soler-Rivas C., Marín F.R., Santoyo S., García-Risco M.R., Señoráns F.J., Reglero G.Testing and enhancing the in vitro bioaccessibility and bioavailability of Rosmarinus officinalis extracts with a high level of antioxidant abietanes

Journal of Agricultural and Food Chemistry, 58 (2010), pp. 1144-1152

Vicente G., Martín D., García-Risco M.R., Fornari T., Reglero G.Supercritical carbon dioxide extraction of antioxidants from rosemary (Rosmarinus officinalis) leaves for use in edible vegetable oils

Journal of Oleo Science, 61 (2012), pp. 689-697

Viuda-Martos M., Ruiz-Navajas Y., Fernandez-Lopez J., Perez-Alvarez J.A.Antibacterial activity of different essential oils obtained from spices widely used in Mediterranean diet International Journal of Food Science and Technology, 43 (2008), pp. 526-531

Waldner M., Neurath M.Novel cytokine-targeted therapies and intestinal inflammation Current Opinion in Pharmacology, 9 (2009), pp. 702-707

Watanabe F., Satsu H., Mochizuki T., Nakano T., Shimizu M.Development of the method for evaluating protective effect of food factors on THP-1-induced damage to human intestinal Caco-2 monolayers

Biofactors (Oxford, England), 21 (2004), pp. 145-147 

chromatography method for determination of carnosic acid in rat plasma and its application to pharmacokinetic study

Biomedical Chromatography, 23 (2009), pp. 776-781

Yu M.H., Choi J.H., Chae I.G., Im H.G., Yang S.A., More K., Lee I.S., Lee J.Suppression of LPSinduced inflammatory activities by Rosmarinus officinalis $\mathbf{L}$

Food Chemistry, 136 (2013), pp. 1047-1054

Zhang C.The role of inflammatory cytokines endothelial dysfunction

Basic Research Cardiology, 103 (2008), pp. 398-406

Zorrilla P., Rodriguez-Nogales A., Algieri F., Garrido-Mesa N., Olivares M., Rondón D., Zarzuelo A., Utrilla M.P., Galvez J., Rodriguez-Cabezas M.E.Intestinal anti-inflammatory activity of the polyphenolic-enriched extract Amanda ${ }^{\circledR}$ in the trinitrobenzenesulphonic acid model of rat colitis

Journal of Functional Foods, 11 (2014), pp. 449-459 